\title{
Limitations to antiarrhythmic drug use in patients with atrial fibrillation
}

\author{
Karin H. Humphries, Charles R. Kerr, Michael Steinbuch, Paul Dorian, for the Canadian Registry \\ of Atrial Fibrillation (CARAF) Investigators
}

ß S See related article page 752

Abstract

Background: Of the antiarrhythmic agents currently marketed in Canada, 5 are commonly used to treat atrial fibrillation (AF). The impact of contraindications, warnings and precautions for the use of these drugs in patients with AF is not known. We evaluated the proportion of patients with AF for whom contraindications, warnings and/or precautions might limit the use of these commonly prescribed drugs and the proportion of patients actually receiving antiarrhythmic drugs despite the presence of contraindications and/or warnings.

Methods: A total of 723 patients with electrocardiographically confirmed, new-onset paroxysmal AF who were enrolled in the Canadian Registry of Atrial Fibrillation were used in this analysis. The 1996 Compendium of Pharmaceuticals and Specialties was used to obtain contraindications, warnings and precautions for use of 5 antiarrhythmic drugs: flecainide, quinidine, sotalol, amiodarone and propafenone. Proportions of patients with contraindications, warnings and/or precautions for use of any of these drugs owing to comorbid conditions or concomitant drug therapy were calculated, regardless of whether the drugs had been prescribed. We then calculated the proportion of patients taking each antiarrhythmic drug at 3 months despite contraindications and/or warnings.

Results: At baseline, when conditions for contraindications and warnings were combined, 414 (57\%), 235 (33\%), 327 (45\%), $285(39 \%)$ and $272(38 \%)$ patients had restrictions for the use of flecainide, quinidine, sotalol, amiodarone and propafenone respectively. Among 465 patients actually taking these medications at 3-month follow-up, 33.3\% (2/6), 83.3\% (40/48), 36.4\% (92/253), 64.1\% (25/39) and 34.5\% (41/119) respectively had contraindications and/or warnings against their use. The burden of comorbid disease among patients with AF was noteworthy: 404 (56\%) had structural heart disease, which included 227 $(31 \%)$ with ischemic heart disease, 158 (22\%) with left ventricular systolic dysfunction and 106 (15\%) with heart failure.

Interpretation: The high burden of comorbid disease and concomitant drug use in a large proportion of patients with AF limits the suitability of existing antiarrhythmic drugs. Over one-third of patients with new-onset AF received antiarrhythmic drugs despite the presence of contraindications or warnings. Although such restrictions may not preclude the use of these drugs, the results demonstrate the need for new antiarrhythmic drugs with fewer limitations.

CMAI 2004;171(7):741-5
A trial fibrillation (AF) is the most frequently encountered sustained arrhythmia in clinical practice and accounts for more physician visits and hospital days than any other cardiac arrhythmia. ${ }^{1}$ Although it is usually not life-threatening, AF is associated with substantial morbidity and increased mortality, largely because of the increased risk of stroke and thromboembolic events..$^{2-4}$

Maintenance of sinus rhythm by means of cardioversion and use of antiarrhythmic drugs is often the initial therapy for $\mathrm{AF},{ }^{5}$ although the results of recent randomized controlled trials have cast doubt on whether rhythm control should be routinely applied in patients with atrial fibrillation or flutter. ${ }^{6,7}$ Several factors are offered as justification for the use of antiarrhythmic drug therapy: symptoms can substantially impair quality of life, ${ }^{8,9}$ lack of active atrial transport and irregular, frequently rapid ventricular rates may result in reduced exercise capacity, dyspnea and cardiomyopathy; and the risk of stroke and thromboembolism is increased, owing to incomplete atrial emptying and stasis in the noncontracting atria. ${ }^{10}$

Of the antiarrhythmic agents approved for use in Canada, 5 are prescribed relatively commonly. All 5 are indicated for ventricular arrhythmias, and 2 (flecainide and quinidine) are approved for supraventricular arrhythmias (SVA) in patients without structural heart disease. Sotalol, propafenone and amiodarone, although not officially approved for SVA in Canada, are the antiarrhythmic agents most commonly prescribed for AF.,11 Each drug has labelling that identifies contraindications, warnings and precautions for use in the setting of cardiac and noncardiac conditions. The frequency of these restrictions and the extent to which these drugs are used despite restrictions among patients with $\mathrm{AF}$ are not known. To address this problem we sought to describe the frequency and impact of contraindications and warnings among patients in whom the use of antiarrhythmic drugs would likely be contemplated.

\section{Methods}

The Canadian Registry of Atrial Fibrillation (CARAF) cohort was used for the analysis. Detailed methods of the registry have been reported elsewhere. ${ }^{12-14}$ Briefly, the registry began to enroll patients in 1991 in 6 cities across Canada; enrollment was 
completed in 1996. Patients were enrolled at the time that AF or atrial flutter was confirmed by electrocardiogram (ECG) through routine, consistent screening of patients in emergency departments and in-hospital patients as well as referrals from general practitioners.

Trained study nurses performed comprehensive baseline and 3-month follow-up evaluations. A set of standardized data forms was used to obtain clinical information. ECGs and echocardiograms were done on all patients at baseline, and ECGs were repeated annually. All medications were carefully documented, and any interventions were recorded.

A total of 899 patients were enrolled in CARAF. The current analyses are limited to patients with paroxysmal AF or atrial flutter, defined as an episode of AF confirmed by ECG documentation with subsequent demonstration of reversion to sinus rhythm. Patients who progressed to chronic AF by the 3-month follow-up, defined as ECG documentation of AF on 2 consecutive ECGs separated by a minimum of 1 week, were excluded from the analysis $(n=136)$, as were patients who did not complete the 3 -month visit $(n=24)$, patients who withdrew from the study before the 3month visit $(n=4)$ and patients who died before the 3 -month visit $(n=12)$. The final study cohort numbered 723 patients, of whom $84(11.6 \%)$ had atrial flutter.

Cardiac and noncardiac conditions and concomitant medication use were retrospectively evaluated from prospectively collected data. Cardiac conditions included bradycardia, recent acute myocardial infarction (MI), history of MI and structural heart disease. Noncardiac conditions included renal disease, pulmonary disease, liver disease, thyroid dysfunction and diabetes mellitus. The antiarrhythmic medications examined were flecainide, quini- dine, sotalol, propafenone and amiodarone. Concomitant medication use focused on digoxin, warfarin, verapamil or diltiazem at diagnosis and at 3-month follow-up.

Bradycardia was defined as an ECG documentation of heart rate $<50$ beats/min in sinus rhythm. History of $\mathrm{MI}$, coronary artery bypass surgery, balloon angioplasty, angina and heart failure were determined on the basis of patient self-report and documented history. Echocardiogram findings were used to determine the presence of left ventricular systolic dysfunction and left ventricular hypertrophy. Structural heart disease was defined as the presence of any of ischemic heart disease, significant valvular heart disease, congenital heart disease, heart failure, cardiomyopathy, left ventricular hypertrophy or left ventricular systolic dysfunction. Valvular heart disease was defined as either a patient-reported history of valvular heart disease or an echocardiogram indicating moderate or severe valvular abnormalities. Cardiomyopathy was determined on the basis of patient self-report and medical records. Renal disease and liver disease were determined on the basis of patient self-report. Thyroid dysfunction was defined as a history of hyperthyroidism or hypothyroidism or abnormal levels of thyroxine or thyroid stimulating hormone.

Contraindications to and warnings and precautions against the use of the 5 antiarrhythmic medications were taken from Canadian labelling as compiled in the 1996 Compendium of Pharmaceuticals and Specialties (CPS) (Table 1). The CPS was chosen as the standard for this assessment because it is the source most used by physicians in their day-to-day practice. Although the CPS does not provide precise definitions for its categories, it is understood that contraindications are of greater concern than warnings,

\begin{tabular}{|c|c|c|c|c|c|}
\hline Condition/concomitant drug use & Flecainide & Quinidine & Sotalol & Amiodarone & Propafenone \\
\hline \multicolumn{6}{|l|}{ Cardiac conditions } \\
\hline Bradycardia* & W & W & $\mathrm{C}$ & $\mathrm{C}$ & $\mathrm{C}$ \\
\hline Recent acute MI & - & - & W & - & - \\
\hline History of MI & W & W & W & W & W \\
\hline Structural heart disease $\dagger$ & $\mathrm{C}$ & - & - & - & - \\
\hline Ischemic heart disease & $\mathrm{C}$ & - & - & - & - \\
\hline Left ventricular systolic dysfunction & $\mathrm{C}$ & - & W & - & - \\
\hline Congestive heart failure & $\mathrm{C}$ & $\mathrm{C}$ & $\mathrm{C}$ & $\mathrm{P}$ & $\mathrm{C}$ \\
\hline \multicolumn{6}{|l|}{ Noncardiac conditions } \\
\hline Renal disease & $\mathrm{P}$ & W & $\mathrm{C}$ & $\mathrm{P}$ & $P$ \\
\hline Pulmonary disease & - & - & $\mathrm{C}$ & $\mathrm{C}$ & $\mathrm{C}$ \\
\hline Liver disease & $\mathrm{P}$ & - & - & $\mathrm{C}$ & $\mathrm{P}$ \\
\hline Thyroid dysfunction & - & - & - & $\mathrm{C}$ & - \\
\hline Diabetes mellitus & - & - & $P$ & - & - \\
\hline \multicolumn{6}{|l|}{ Concomitant drug use } \\
\hline Digoxin & $\mathrm{P}$ & $\mathrm{C}$ & $P$ & $P$ & $P$ \\
\hline Warfarin & - & $P$ & - & $P$ & $P$ \\
\hline Verapamil & - & $\mathrm{P}$ & $P$ & - & - \\
\hline Diltiazem & - & $\mathrm{P}$ & $P$ & - & - \\
\hline
\end{tabular}

Notes: $\mathrm{C}=$ contraindication, $\mathrm{W}=$ warning, $\mathrm{P}=$ precaution, $\mathrm{Ml}=$ myocardial infarction

*Heart rate $<50$ beats/min in normal sinus rhythm.

†The CPS does not define structural heart disease as including ischemic heart disease, left ventricular systolic dysfunction and congestive heart failure, and therefore these conditions are shown here as separate items. 
which in turn are of greater concern than precautions when considering medication choices.

The prevalence of each condition of interest was computed for all patients. Subsequently, 3 composite proportions were calculated for patients who might not be suitable for antiarrhythmic therapies owing to contraindications; contraindications and/or warnings; or contraindications and/or warnings and/or precautions, including concomitant drug use.

We then examined actual medication use at 3 months and calculated the proportion of patients taking antiarrhythmic medications despite contraindications and/or warnings. Adverse events in patients with and without contraindications and/or warnings were compared using Fisher's Exact test.

\section{Results}

The median age of the 723 patients included in this analysis was 64 years (interquartile range $53-71) ; 278$ $(38.5 \%)$ were female. Most patients $(600,83 \%)$ were symptomatic at presentation. Overall, at baseline 404 (56\%) of the patients had structural heart disease, which included 227 (31\%) with ischemic heart disease, 158 (22\%) with left ventricular systolic dysfunction and $106(15 \%)$ with heart failure. Although concomitant use of digoxin and warfarin was infrequent at diagnosis, it increased to $332(46 \%)$ and $253(35 \%)$ patients respectively at 3 months (Table 2).

Overall, 414 (57\%) and 235 (33\%) patients had contraindications and/or warnings at baseline that might prevent the use of flecainide and quinidine respectively (Table $3)$. After including precautions, these numbers increased to $421(58 \%)$ and 262 (36\%) respectively. Although sotalol, amiodarone and propafenone are not indicated for use in patients with SVAs in Canada, they are widely used for AF in Canada and other countries. Overall, 327 (45\%), 285 $(39 \%)$ and $272(38 \%)$ patients had contraindications and/or warnings that might limit the use of sotalol, amiodarone and propafenone respectively. After including precautions, these numbers increased to 380 (53\%), $336(46 \%)$ and 296 $(41 \%)$ respectively.

A total of $465(64 \%)$ patients were actually taking antiarrhythmic drug therapy at 3 months. We determined the proportion with contraindications and/or warnings (Table 4). Of 48 patients taking quinidine, 40 (83\%) had contraindications and/or warnings, and of 39 patients taking amiodarone, 25 (64\%) had contraindications and/or warnings. One-third of patients taking flecainide, sotalol and propafenone received these medications despite contraindications and/or warnings. Of interest, none of the patients taking flecainide had atrial flutter, although $20(8.5 \%)$ patients taking propafenone did, 10 with contraindications and/or warnings and 10 without. $^{15}$

Even though CARAF was neither designed nor powered to assess adverse events, we examined the rates of medication discontinuation, pacemaker implantation and bleeding among patients with contraindications and/or warnings and among those without. There were no significant differences with respect to discontinuation of medications; $2 \%$ of patients concomitantly taking both warfarin and amiodarone had a bleed (experiencing $>20 \mathrm{~g} / \mathrm{L}$ drop in hemoglobin levels or requiring a transfusion), compared with $1.6 \%$ of patients not taking both drugs. Similarly, $1.4 \%$ of patients taking warfarin and propafenone had a bleed, compared with $1.1 \%$ not taking both drugs. Of potential interest is that $2(8 \%)$ patients taking sotalol and verapamil had a pacemaker implant, compared with $77(2.5 \%)$ of those not taking this combination of medications $(p=0.21)$.

\section{Interpretation}

In a large cohort of patients with an initial diagnosis of paroxysmal AF, a substantial portion of patients had comorbidities and conditions that might limit the use of currently available antiarrhythmic therapies. When considering any contraindications, warnings or precautions as well as concomitant drug use, between $36 \%$ and $58 \%$ of patients had limitations for the use of all 5 antiarrhythmic drugs.

\begin{tabular}{|c|c|}
\hline Condition/concomitant drug use & $\begin{array}{l}\text { No. }(\%) \text { of patients } \\
\quad(n=723)\end{array}$ \\
\hline \multicolumn{2}{|l|}{ Cardiac conditions } \\
\hline Bradycardia & $26 \quad(3.6)$ \\
\hline Recent acute MI & $49 \quad(6.8)$ \\
\hline History of MI & $143(19.8)$ \\
\hline Structural heart disease $†$ & $404(55.9)$ \\
\hline Ischemic heart disease & $227(31.4)$ \\
\hline Left ventricular systolic dysfunction & $158(21.9)$ \\
\hline Congestive heart failure & $106(14.7)$ \\
\hline \multicolumn{2}{|l|}{ Noncardiac conditions } \\
\hline Renal disease* & $3(0.4)$ \\
\hline Pulmonary disease & $99(13.7)$ \\
\hline Liver disease* & $1 \quad(0.1)$ \\
\hline Thyroid dysfunction & $67 \quad(9.3)$ \\
\hline Diabetes mellitus & $64 \quad(8.9)$ \\
\hline \multicolumn{2}{|l|}{ Concomitant drug use at baseline } \\
\hline Digoxin & $49 \quad(6.8)$ \\
\hline Warfarin & 19 (2.6) \\
\hline Verapamil & $9 \quad(1.2)$ \\
\hline Diltiazem & $52(7.2)$ \\
\hline \multicolumn{2}{|l|}{ Concomitant drug use at 3-mo follow-up } \\
\hline Digoxin & $332(45.9)$ \\
\hline Warfarin & $253(35.0)$ \\
\hline Verapamil & $41 \quad(5.7)$ \\
\hline Diltiazem & $47 \quad(6.5)$ \\
\hline
\end{tabular}

*Data derived from patient self-report.

†For our study we have defined structural heart disease as including ischemic heart disease, significant valvular heart disease, congenital heart disease, heart failure, cardiomyopathy, left ventricular hypertrophy and left ventricular systolic dysfunction. Several patients had more than 1 of the conditions listed. 
Although precautions or warnings may not preclude use, their presence does suggest caution when antiarrhythmic treatment is being considered. Labelling also has medicolegal implications when a drug is not formally approved for use in specific conditions.

Of patients taking antiarrhythmic drugs, over onethird had contraindications and/or warnings. A post hoc assessment of adverse events did not identify an association with medication use in the presence of contraindications and/or warnings. Failure to demonstrate adverse events in these patients may reflect the retrospective assessment of adverse events as well as the limited sample size. Another possibility is that practising physicians appropriately weigh contraindications and warnings against other, unmeasured factors when choosing medications for individual patients.

The results of Atrial Fibrillation Follow-up Investigation of Rhythm Management (AFFIRM) ${ }^{7}$ suggest there may be no advantage to antiarrhythmic drug use and that rate control may be the preferred therapeutic approach. However, it is important to recognize that AFFIRM excluded patients who did not obtain adequate symptom relief from rate control and thus may not be representative of the majority of patients with $\mathrm{AF}$, namely symptomatic patients for whom symptom relief is an important goal of therapy. In this CARAF cohort, $83 \%$ were symptomatic at presentation.

The current study is limited by the lack of prospectively collected information on renal disease, liver dis-

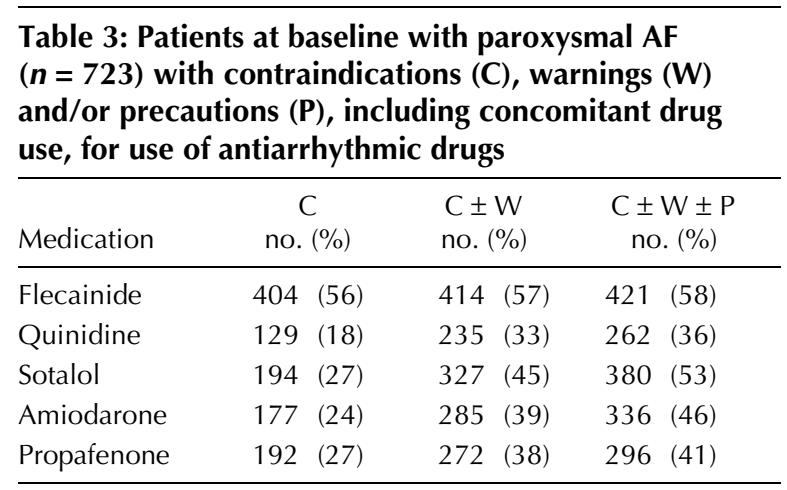

\begin{tabular}{|c|c|c|}
\hline Medication & $\begin{array}{l}\text { No. of } \\
\text { patients }\end{array}$ & $\begin{array}{c}\text { No. (and \%) of } \\
\text { patients with } \mathrm{C} \pm \mathrm{W}\end{array}$ \\
\hline Flecainide & 6 & $2(33.3)$ \\
\hline Quinidine & 48 & $40(83.3)$ \\
\hline Sotalol & 253 & $92(36.4)$ \\
\hline Amiodarone & 39 & $25(64.1)$ \\
\hline Propafenone & 119 & $41(34.5)$ \\
\hline
\end{tabular}

ease, severity of congestive heart failure (e.g., New York Heart Assciation class), laboratory measures of renal function (e.g., creatinine levels) and liver function. Thus this report may underestimate the prevalence of limitations to drug use. Similarly, the study was not designed to evaluate adverse events, and we may have underestimated such events. These data are being collected in an ongoing study with a similar cohort of patients with $\mathrm{AF}$ (CARAF II), which should be able to provide better estimates of the frequency of restrictions that result from comorbid conditions and adverse events. We chose not to examine disopyramide, procainamide or dofetilide, since the use of disopyramide and procainamide is extremely limited and dofetilide has not been approved for use in Canada at this time.

In summary, in a large cohort of patients with newonset $\mathrm{AF}$ who potentially required antiarrhythmic medication therapy, a substantial portion had contraindications and/or warnings for the use of currently available drugs. Among patients using antiarrhythmic medications, over one-third had contraindications and/or warnings for their use. These findings highlight the need for new agents that are more "friendly" to use ${ }^{16}$ in the treatment of $\mathrm{AF}$, since many patients with $\mathrm{AF}$ have extensive comorbid conditions and require symptom relief not provided by rate control.

\section{This article has been peer reviewed.}

From the Department of Medicine, University of British Columbia (Humphries, Kerr); the Centre for Health Evaluation \& Outcomes Sciences (Humphries), Vancouver, BC; Health Care Research Center, Procter and Gamble Pharmaceuticals Inc., Mason, Ohio (Steinbuch); and the Department of Medicine, University of Toronto, Toronto, Ont. (Dorian)

\section{Competing interests: None declared.}

Contributors: Karin Humphries carried out the analyses, interpreted the results, wrote the draft manuscript and incorporated all changes and edits from the authors and from CMA7 reviewers. Charles Kerr conceived the idea for the study, helped design it and revised the draft for critically important content. Michael Steinbuch was involved in the development of the study idea, contributed the data regarding contraindications, warnings and precautions, and revised the draft of the manuscript. Paul Dorian helped refine the study question and interpret the results and contributed critically to important intellectual content. All authors gave final approval of the version to be published.

Acknowledgements: We would like to acknowledge the CARAF Study Coordinators - Diane Skippen, Vancouver; Debbie Ritchie, Calgary; Bonnie Spindler, London; Susan Morgan, Hamilton; Marilynn Luce, Ottawa; and Danielle Beaudoin, Montreal - for their dedication to this study. In particular, we would like to thank Susan Mooney, for overseeing data collection and verifying all data entry. Without their dedication and support this study would not be possible.

This project was supported by an unrestricted grant from Procter and Gamble Pharmaceuticals Inc. (1998-2002). Knoll Pharmaceuticals (1991-1997) and Dupont Pharma (1996) previously supported CARAF.

\section{References}

1. Bialy D, Lehmann M, Schumacher D. Hospitalization for arrhythmias in the United States: importance of atrial fibrillation. 7 Am Coll Cardiol 1992;19:14a.

2. Benjamin EJ, Wolf PA, D'Agostino RB, Silbershatz H, Kannel WB, Levy D. Impact of atrial fibrillation on the risk of death: the Framingham Heart Study. Circulation 1998;98(10):946-52.

3. Connolly SJ, Laupacis A, Gent M, Roberts RS, Cairns JA, Joyner C. Canadian Atrial Fibrillation Anticoagulation (CAFA) Study. 7 Am Coll Cardiol 1991;18(2):349-55.

4. SPAF I Investigators. Stroke Prevention in Atrial Fibrillation Study. Final results. Circulation 1991;84(2):527-39. 
5. Falk RH. Atrial fibrillation. N Engl f Med 2001;344(14):1067-78.

6. Hohnloser SH, Kuck KH. Randomized trial of rhythm or rate control in atrial fibrillation: the Pharmacological Intervention in Atrial Fibrillation Trial (PIAF). Eur Heart 7 2001;22(10):801-2.

7. AFFIRM Investigators. A Comparison of Rate Control and Rhythm Control in Patients with Atrial Fibrillation. N Engl 7 Med 2002;347:1825-33.

8. Dorian P, Jung W, Newman D, Paquette M, Wood K, Ayers GM, et al. The impairment of health-related quality of life in patients with intermittent atrial fibrillation: implications for the assessment of investigational therapy. $7 \mathrm{Am}$ Coll Cardiol 2000;36(4):1303-9.

9. Dorian P, Paquette M, Newman D, Green M, Connolly SJ, Talajic M, et al. Quality of life improves with treatment in the Canadian Trial of Atrial Fibrillation. Am Heart 7 2002;143(6):984-90.

10. Jung F, DiMarco JP. Antiarrhythmic drug therapy in the treatment of atrial fibrillation. Cardiol Clin 1996;14(4):507-20.

11. Roy D, Talajic M, Dorian P, Connolly S, Eisenberg MJ, Green M, et al. Amiodarone to prevent recurrence of atrial fibrillation. Canadian Trial of Atrial Fibrillation Investigators. N Engl f Med 2000;342(13):913-20.

12. Humphries KH, Kerr CR, Connolly SJ, Klein G, Boone JA, Green M, et al. New-onset atrial fibrillation: sex differences in presentation, treatment, and outcome. Circulation 2001;103(19):2365-70.

13. Kerr C, Boone J, Connolly S, Greene M, Klein G, Sheldon R, et al. Followup of atrial fibrillation: The initial experience of the Canadian Registry of Atrial Fibrillation. Eur Heart 7 1996;17 Suppl C:48-51.

14. Kerr CR, Boone J, Connolly SJ, Dorian P, Green M, Klein G, et al. The Canadian Registry of Atrial Fibrillation: a noninterventional follow-up of patients after the first diagnosis of atrial fibrillation. Am 7 Cardiol 1998;82(8A):82N-5N.
15. Murdock C, Kyle A, Yeung-Lai-Wah J, Qi A, Vorderbrugge S, Kerr C. Atrial flutter in patients treated for atrial fibrillation with propafenone. Am 7 Cardio 1990;66:755-7.

16. Friedman PL, Stevenson WG. Proarrhythmia. Am 7 Cardiol 1998;82(8A): $50 \mathrm{~N}-8 \mathrm{~N}$.

Correspondence to: Dr. Karin H. Humphries, Centre for Health Evaluation \& Outcomes Sciences, 620B-1081 Burrard St., Vancouver BC V6Z1Y6; fax 604 806-8674; khumphries@ providencehealth.bc.ca

Canadian Registry of Atrial Fibrillation (CARAF) Investigators: Charles R. Kerr, St. Paul's Hospital and the University of British

Columbia, Vancouver, BC; Robert Sheldon, University of Calgary, Calgary, Alta.; George Klein, University of Western Ontario, London, Ont.; Stuart Connolly, Hamilton General Hospital, Hamilton, Ont.; Martin Green, Ottawa Heart Institute, Ottawa, Ont.; Mario Talajic, Montreal Heart Institute, Montréal, Que.; Paul Dorian, St. Michael's Hospital, and the University of Toronto, Toronto, Ont.; David Newman, St. Michael's Hospital and the University of Toronto, Toronto Ont.

\section{Canadian Medical Association}

\author{
2005 Special Awards - Call for Nominations
}

\section{Association médicale canadienne}

Prix spéciaux pour l'an 2005 - Appel de candidatures
The Canadian Medical Association invites nominations for the 2005 special awards.

- Medal of Honour

- F.N.G. Starr Award

- Medal of Service

- May Cohen Award for Women Mentors

- Sir Charles Tupper Award for Political Action

- Award for Excellence in Health Promotion

- CMA Award for Young Leaders

Refer to the "Awards from CMA" section on cma.ca for detailed criteria on each of the awards or contact the awards co-ordinator at $1800663-7336$, ext. 2280.

Nominations should be submitted to:

Chair, Committee on Archives c/o Committee Co-ordinator Strategic and Corporate Affairs Canadian Medical Association 1867 Alta Vista Drive Ottawa, ON K1G 3 Y6

Closing date for receipt of nominations is Nov. 30, 2004.
L'Association médicale canadienne sollicite des candidatures à ses prix spéciaux pour l'an 2005.

- Médaille d'honneur

- Prix F.N.G. Starr

- Médaille de service

- Prix May-Cohen pour femmes mentors

- Prix Sir-Charles-Tupper d'action politique

- Prix d'excellence de l'AMC en promotion de la santé

- Prix des jeunes chefs de file de l'AMC

Voir «Prix et distinctions de l'AMC» sur le site amc.ca pour les critères détaillés de chaque prix ou contacter la coordonnatrice des prix au 1800 663-7336, poste 2280 .

Les candidatures doivent être soumises au :

Président, Comité des archives a/s Coordonnatrice des comités Affaires générale et Stratégiques Association médicale canadienne 1867, promenade Alta Vista Ottawa (Ontario) K1G 3 Y6

Les candidatures doivent être présentées au plus tard le 30 novembre 2004 . 